Programa de Residência Pedagógica na Licenciatura em Informática: partilhando possibilidades

\title{
AULA DE INFORMÁTICA EM ESCOLA SEM LABORATÓRIO: RELATO DE EXPERIÊNCIA DO PROGRAMA DE RESIDÊNCIA PEDAGÓGICA
}

Lucas Mateus Barbalho de Souzaㄹ, Breno Trajano de Almeida²

\section{PALAVRAS-CHAVE}

Computação desplugada;

Experiência Docente;

Laboratório de aprendizagem.

\section{RESUMO}

O presente artigo tem como objetivo apresentar o ensino de informática básica de maneira desplugada, conceito desenvolvido por Tim Bell, Lan H. Witten e Mike Fellows (2011) e que foi aplicado na disciplina de língua portuguesa na Escola Estadual Manoel de Melo Montenegro, localizada na cidade de Ipanguaçu/RN. O referido trabalho é um relato da experiência realizado por graduandos do curso Licenciatura em Informática do Instituto Federal de Educação, Ciência e Tecnologia do Rio Grande do Norte (IFRN), Campus Ipanguaçu. Os bolsistas do Programa de Residência Pedagógica mediaram conceitos de informática em uma escola sem laboratório e sem o uso de hardware ou de software. A experiência realizada possibilitou aula lúdica e interativa trabalhando conceitos de forma interdisciplinar.

\section{INTRODUÇÃO}

Desde o final da década de 1990, a nossa sociedade vem passando por profundas transformações tecnológicas que exigem mudanças significativas nos mais diversos segmentos. Dentre estes, a educação brasileira apresenta uma necessidade de trilhar novos caminhos em busca dessa adaptação. (ALMEIDA, 2013).

Visando a implementação das políticas de disseminação de novas Tecnologias da Informação e Comunicação (TICs) nas escolas públicas de educação básica, o Governo Federal criou, em 1997, o Programa Nacional de Formação Continuada em Tecnologia Educacional (PROINFO), com o objetivo de proporcionar a inclusão digital de professores, gestores e a comunidade escolar em geral. O programa faz a articulação e a distribuição de equipamentos tecnológicos para as escolas, tais como, computadores e impressoras, além de ofertar cursos de formação por meio do portal do professor, TV escola etc.

\footnotetext{
${ }^{1}$ Graduando do Curso Superior de Licenciatura em Informática no Instituto Federal de Educação, Ciência e Tecnologia do Rio Grande do Norte (IFRN) - Campus Ipanguaçu. E-mail: luskkamatheus@ gmail.com

2 Professor Efetivo do Instituto Federal de Educação, Ciência e Tecnologia do Rio Grande do Norte (IFRN) - Campus Ipanguaçu; Orientador do Programa Residência Pedagógica. E-mail: breno.almeida@ifrn.edu.br
} 


\section{Lucas Mateus E Breno Trajano}

Mesmo com a inclusão das TICs nas escolas, algumas não têm todo aparato necessário para a sua utilização. A Escola Estadual Manoel de Melo Montenegro, localizada na cidade de Ipanguaçu/RN, a qual foi realizada a experiência deste estudo, não possui laboratório de informática. As suas salas de aulas têm poucas tomadas, o que dificulta o uso de projetor multimídia, necessitando de extensões para o seu funcionamento. A escola dispõe de uma lousa digital, porém, o instrumento está guardado por não haver quem o instale. $\mathrm{O}$ acesso à internet é precário sendo restrito apenas à administração.

Partindo dessas constatações, surgiu a questão problema: Como ministrar aula de informática em uma escola sem laboratório? Com isso, o objetivo deste estudo é mostrar o ensino de informática básica de maneira desplugada, conceito desenvolvido por Tim Bell, Lan H. Witten e Mike Fellows (2011) e que pode tornar as aulas mais lúdicas usando meios analógicos do cotidiano sem o uso de recursos digitais como hardware e/ ou software.

Como a informática ainda não faz parte do currículo das escolas públicas de educação básica e, em consequência, não se tem um espaço direcionado para se trabalhar com recursos digitais, inserimos os conceitos computacionais de forma desplugada, trabalhando lógica, informática básica, formatação de textos etc. Dessa forma, além de inserir a informática no contexto educacional, estes aspectos acabam por divulgar a área de computação como uma possível carreira profissional. (PAES et al., 2010).

A pesquisa se ancora nas experiências vivenciadas por um bolsista residente do Programa de Residência Pedagógica na Escola Estadual Manoel de Melo Montenegro durante as etapas de ambientação, planejamento e regência na escolacampo, realizadas em 2019.

O texto apresenta uma visão panorâmica sobre a discussão das principais dificuldades de inserção da informática nas escolas (ALMEIDA; VALENTE, 1997; ASSMANN, 2000), destacando a computação desplugada à luz dos criadores dessa técnica, citados nesta introdução.

\section{AS DIFICULDADES DE INSERÇÃO DA INFORMÁTICA NAS ESCOLAS}

O uso de programas de informática nas escolas públicas brasileiras pode ser uma oportunidade de apoio nos processos de ensino e aprendizagem e uma forma de disseminar a utilização da tecnologia em favor do desenvolvimento escolar dos estudantes. De acordo com Almeida e Valente (1997) citado por Leite e Braga (2009), Informática na Educação significa a inserção do computador no processo de aprendizagem dos conteúdos curriculares de todos os níveis e modalidades de educação.

A utilização de computadores nos processos de ensino pode gerar mudanças pedagógicas significativas, possibilitando a criação de novos ambientes educacionais facilitadores da metodologia usada no processo de aprendizagem. O grande desafio é a mudança da abordagem educacional de transformar uma educação centrada no 


\section{Lucas Mateus E Breno Trajano}

ensino e na transmissão da informação, para uma educação em que o aluno pudesse realizar atividades através do computador e, assim, aprender. (LEITE; BRAGA, 2009).

A mudança na abordagem educacional não seria o único desafio. Para Assmann (2000) citado por Dantas e Costa (2013, p. 3), existe uma resistência de muitos professores em utilizar as tecnologias como facilitadora dentro da sala de aula devido "a insegurança derivada do falso receio de estar sendo superado/a, no plano cognitivo, pelos recursos instrumentais da informática". Além disso, a inclusão da informática na escola requer que se tenha uma boa infraestrutura, com espaço que suporte computadores suficientes, internet, energia compatível, boa iluminação, climatização, entre outros, para atender a demanda dos alunos.

Para além da estrutura física, a formação dos professores em relação ao uso das TICs em sala de aula é fundamental, pois embora o Governo Federal tenha criado o PROINFO que viabiliza essa formação, é notório que nem todos os professores têm acesso ou a escola não fomenta essa formação em seu âmbito. Segundo Stinghen (2016, p. 5) o fator capacitação na área da tecnologia vem causando preocupações para muitos professores da rede pública de educação.

De acordo com Amorin (2015), os três maiores desafios para a implementação das TICs em sala de aula são a infraestrutura da escola, a capacitação dos professores e a escolha do material digital. Para esse autor, em relação ao terceiro desafio, não significa apenas utilizar o material pedagógico tradicional em formato digital. $\mathrm{Na}$ realidade, o livro digital precisa e deve ser interativo.

\footnotetext{
Infelizmente grande parte das editoras que oferece conteúdo digital faz apenas isso, transforma os livros físicos em versões PDF, o que não muda nada na apreensão do assunto, afinal ele só estará escrito em outra mídia (no tablet e não no papel). Conteúdo vai além disso, é preciso pensar nele como algo atrativo, flexível, de qualidade. (AMORIM, 2015, p. 17).
}

Além disso, é necessário que o material tal como a capacitação dos professores, sejam propostas educacionais predefinidas pelas escolas, e que sejam promovidas experiências que tornem o aprendizado mais dinâmico e contextualizado, oferecendo também feedback avaliativo.

Vale ressaltar que existem meios que permitem trabalhar conteúdos da área da informática na sala de aula sem o uso de computadores ou instrumentos digitais, é o caso da computação desplugada que será discutida no tópico a seguir.

\section{COMPUTAÇÃO DESPLUGADA}

Habitualmente, as escolas propiciam o contato com a informática por meio da exposição de alguns conceitos iniciais e enfatizam atividades práticas, as quais requerem uso dos computadores em laboratórios de informática, tornado assim em primeira instância, atividades atrativas para os alunos. Entretanto, esta abordagem 


\section{Lucas Mateus E Breno Trajano}

pode acarretar limitações importantes por dar a impressão de que a Ciência da Computação se restringe à capacitação do uso de equipamentos e programas computacionais. (VIEIRA, 2013)

$\mathrm{Na}$ perspectiva da Ciência da Computação limitada apenas ao uso de equipamentos digitais, temos o projeto dos autores Tim Bell, Lan H. Witten e Mike Fellows que se tornou o livro Computer Science Unplugged, onde apresenta material para suprir as dificuldades encontradas na disseminação da computação.

Do ponto de vista desses autores sobre o conceito de computação desplugada, eles afirmam que:

[...] Geralmente, as atividades desplugadas envolvem a resolução de problemas para alcançar um objetivo, e, também, no processo de lidar com conceitos fundamentais de Ciência da Computação" (BELL et al, 2009, em livre tradução).

Segundo Souza (2010), tais atividades têm despertado o interesse de professores e pesquisadores, e tem sido empregadas em diversos países ao redor do mundo. Essas atividades consistem, em ensinar os fundamentos da computação, por meio de práticas, sem o uso do computador, sendo essa sua grande vantagem, a independência de recursos de hardware ou software.

Aplicar atividades com conteúdo de computação sem estar na frente do computador garante que os estudantes deixem de ver o computador como um brinquedo ou como uma ferramenta e passem a visualizá-lo como um objeto de estudo, podendo, desta forma, encarar problemas como complexidade do algoritmo, compressão de dados, entre outros. (BELL et al., 2009).

As atividades desplugadas geralmente trabalham com desafios que os estudantes devem resolver por conta própria. Além do princípio fundamental do projeto, que se trata de desenvolver metodologia de ensino para ciência da computação, independente da utilização de computadores, os autores ainda destacam diversos princípios, conforme podemos constatar na Tabela 1. (BELL et al., 2009).

Tabela 1: Princípios para desenvolvimento de métodos da computação desplugada.

\section{Princípios Atividades}

Foco na demonstração de conceitos da ciência Atividades devem ser elaboradas em uma da computação, para reduzir o "gargalo" que a escala que propicie o trabalho em equipe. programação representa nas grades.

As atividades devem ser divertidas e Os materiais utilizados devem ser de baixo envolventes, para que não se tornem uma custo.

obrigação.

Os materiais desenvolvidos para o projeto devem ser distribuídos com uma licença creative commons para que outras pessoas possam utilizá-los, sem enriquecimento próprio, e para incentivar e permitir que um maior número de pessoas possa contribuir 
para o projeto.

O objetivo deve ser sempre incentivar as

crianças a alcançar a resposta por conta

própria, para manter o foco de abstração do

conceito por trás da atividade;

Fonte: elaboração dos autores.

As atividades devem possuir uma tolerância ao erro das crianças, de forma que mesmo que os participantes cometam pequenos erros o resultado principal não seja afetado.

As atividades desplugadas usam diversos tipos de materiais lúdicos, como cartões tipo imã de geladeira, quadro branco, caixas, cartolinas, cronômetro, dentre outros. Bell et al. (2011, apud Vieira, 2013) sugerem diversas atividades, dando dicas das matérias correlatas, das habilidades a serem tratadas, materiais a serem utilizados e, algumas vezes, variações e extensões de como realizar a atividade para outros fins.

Um exemplo do uso da computação desplugada na escola é o projeto Robótica Sucational, desenvolvido em 2017 pelo professor João Paulo Falcão na Escola Pedro Carnaúba, localizada na cidade de Viçosa (Alagoas), que tem o intuito de recolher todo o lixo eletrônico descartado, como celulares, baterias, fones, fios, entre outros e transformá-los em objetos a exemplo de mini robôs.

De acordo com o professor João Paulo Falcão, o projeto é simples, e tem o objetivo de incentivar os alunos a pesquisar, estudar e transformar o lixo em ciência (SOUZA, 2019). O Robótica Sucational também é uma proposta de dinamizar as aulas e motivar os alunos, considerando que o projeto contava com mais de 750 estudantes e com mais 1800 quilos de resíduos eletrônicos coletados, demonstração que nos serve de exemplo.

\section{EXPERIÊNCIA REALIZADA NA ESCOLA-CAMPO.}

Durante o Programa de Residência Pedagógica (PRP), os bolsistas residentes devem atuar dentro da escola-campo executando etapas exigidas pelo Programa, entre as quais a imersão e a regência, ambas com carga horária definida previamente.

A experiência deste estudo foi realizada na Escola Estadual Manoel de Melo Montenegro, localizada na cidade de Ipanguaçu/RN, que oferece turmas em tempo integral. O componente curricular do qual houve atuação mais direta foi o de Língua Portuguesa, onde o bolsista/residente teve todo o acompanhamento da professora titular da disciplina e da professora preceptora.

Durante a etapa de imersão, o bolsista/ residente observou as aulas nas turmas da $3^{\text {a }}$ série do ensino médio, em que os conteúdos ministrados estavam direcionados para a escrita da redação do Exame Nacional do Ensino Médio (ENEM) de 2019. Segundo o Guia de Aprendizagem elaborado pela professora titular, os conteúdos que estavam sendo abordados eram:

- Estratégias Argumentativas;

- Formas de iniciar o texto;

- Tabela de conectivos e funções na redação; 


\section{Lucas Mateus E Breno Trajano}

- Cartão com as cinco competências analisadas na redação do ENEM;

- Vídeos Motivacionais;

- Análises de Textos Reflexivos e Informativos;

- Análises de Poemas e Músicas.

Partindo disso, o residente elaborou uma aula junto com a referida professora e com o apoio da preceptora, que tinha como objetivo compreender a estrutura da redação e formatação de texto. A aula tinha como base os conteúdos já estudados em sala e seria mais especificamente uma revisão de forma prática dos conteúdos já abordados.

O desafio encontrado pelo residente foi em como ministrar a aula de formatação de texto sem o uso do computador, já que a escola-campo não dispõe de um laboratório de informática. Para tanto, ele utilizou a técnica da computação desplugada, que consiste em ensinar ciência da computação sem o uso de hardware e/ ou software.

Para subsidiar o planejamento da técnica da computação desplugada, o residente utilizou artigos sobre a temática disponibilizados na web. Com base na leitura dos artigos, a metodologia foi organizada de forma dinâmica, conforme exposto na Tabela 2, tendo como objetivo também de entreter os alunos em sala de aula.

Tabela 2: Processo de planejamento da regência sobre Computação desplugada.

\begin{tabular}{|c|l|}
\hline Passo 1 & $\begin{array}{l}\text { Foram escolhidas duas redações do Enem de anos anteriores, de autores } \\
\text { diferentes e que abordavam o mesmo tema. }\end{array}$ \\
\hline Passo 2 & $\begin{array}{l}\text { Deixar os textos das redações sem formatação, ou seja, sem parágrafo, } \\
\text { espaçamento simples, tamanho e fonte também foram alterados. }\end{array}$ \\
\hline Passo 3 & $\begin{array}{l}\text { Recortar os textos em várias partes e colocá-los misturados dentro de } \\
\text { envelopes. }\end{array}$ \\
\hline
\end{tabular}

Fonte: elaboração dos autores.

Diante disso, foi realizada a regência do residente nas turmas das $3^{\mathrm{a}}$ séries $\mathrm{A}$ e B do ensino médio, da escola-campo mencionada. De início, explicou-se como seria a dinâmica da aula e, em seguida, foi abordado pela professora titular alguns pontos dos conteúdos que já haviam sido trabalhados em sala, tais como estrutura da redação do ENEM e os verbos de ligação dos parágrafos. Logo após, o residente teceu argumentos sobre a formatação de textos com os alunos, os quais, por já terem concluído o curso técnico em informática que foi ofertado na própria escola há um ano, quando se tinha laboratório de informática, demonstraram domínio nesse conteúdo.

As aulas nas duas turmas aconteceram no mesmo dia, em horários distintos. Antes de entregar os envelopes contendo as redações, os alunos foram divididos em grupos de acordo com a quantidade presente em sala de aula; após a divisão, foi entregue um envelope por grupo e os alunos tiveram o tempo equivalente a um horário da aula para poder montar as duas redações corretamente. 


\section{Lucas Mateus E Breno Trajano}

Em seguida, eles teriam que anotar as dificuldades e os pontos positivos encontrados ao desenvolver a atividade, bem como falar se as redações estavam dentro dos padrões da Associação Brasileira de Normas Técnicas (ABNT), cujo conteúdo foi discutido anteriormente.

Após a conclusão do tempo determinado, foi verificado pelo residente se as redações montadas pelos grupos estavam coerentes com as originais. Seguidamente, cada grupo apresentou para os demais suas dificuldades, pontos positivos e sobre a formatação de texto das redações, momento considerado bastante proveitoso, em que foi possível verificar que o assunto trabalhado em sala estava sendo compreendido, e que os alunos tinham conhecimento sobre o conteúdo formatação de texto atrelado à disciplina de língua portuguesa.

Durante as apresentações, houve relatos sobre a dinâmica ter colaborado significativamente com a compreensão do conteúdo, e sobre o desejo de alunos por mais aulas lúdicas como esta. Os depoimentos reforçaram o entendimento de que é possível fazer uso da técnica da computação desplugada para desenvolver as aulas de informática.

\section{CONSIDERAÇÕES FINAIS}

$\mathrm{O}$ ato de levar a informática para dentro da sala de aula sem o uso dos computadores, smartphones ou qualquer meio tecnológico digital, chama atenção dos educandos e gera especulações de como funcionaria o ensino de informática sem os meios digitais.

Diante disso, a técnica da computação desplugada vem para responder essas possíveis indagações e mostrar que para o ensino de informática, não necessariamente é preciso usar um computador e que, por meio dessa técnica, é possível aprender conceitos básicos dessa área utilizando recursos analógicos que usamos no nosso dia a dia, como papelão, caixas, imãs e o próprio quadro branco da sala de aula.

Por meio da experiência realizada, percebe-se a viabilidade de conectar a área da computação de maneira desplugada com disciplinas de formação geral (propedêuticas) e, desse modo, a informática poderá contribuir nos processos de ensino e de aprendizagem, sendo usada como objeto de estudo e também como auxílio na mediação do docente.

Para formação acadêmica, o uso da computação em sala de aula pode ser essencial, possibilitando outras visões e métodos para o ensino e a aprendizagem. Como o bolsista residente que atuou na experiência é acadêmico no curso de Licenciatura em Informática, essa prática contribuiu para a sua formação, uma vez que o colocou como mediador do conteúdo em uma escola-campo com uma pespectiva totalmente contrária do que é vivenciada no Instituto Federal do Rio Grande do Norte. Levar a informática para uma escola sem laboratório, atrelando a uma disciplina propedêutica, além de ser um grande desafio, instigou ainda mais o fazer docente, principalmente ao escutar os relatos dos alunos após a experiência. 


\section{Lucas Mateus E Breno Trajano}

Assim, espera-se que a técnica da informática desplugada não fique limitada apenas à ciência da computação, mas que ela seja explorada pelos professores das demais áreas de conhecimento de forma que venha contribuir no processo de ensino e, consequentemente, na aprendizagem dos educandos.

\section{REFERÊNCIAS}

ALMEIDA, Breno Trajano de. Planejamento: elemento promotor de mudanças. In: GARCIA, Anderson; ALMEIDA, Breno Trajano de. Educação: diferentes olhares, novos caminhos. Florianópolis/SC, 2013, 17-23.

AMORIM, Americo. Três Desafios na Implantação de Tecnologias em Escolas. 2015. Disponível em: <https://escribo.com/2015/06/16/tres-desafios-naimplantacao-de-tecnologias-em-escolas/>. Acesso em: 22 out. 2019.

BELL, T.; WITTEN, I. e FELLOWS, M. (2011). “Computer Science Unplugged Ensinando Ciência da Computação sem o uso do Computador". Tradução de Luciano Porto Barreto, 2011. Disponível em: http://csunplugged.org/. Acesso em 19/10/2019.

COSTA, Thaíse et al. Trabalhando Fundamentos de Computação no Nível Fundamental: experiência de licenciandos em Computação da Universidade Federal da Paraíba. 2012. Disponível em: <http://www.imago.ufpr.br/csbc2012/anais_csbc/eventos/wei/artigos/Trabalhan do $\% 20$ Fundamentos $\% 20$ de $\% 20$ Computacao $\% 20$ no $\% 20$ Nivel $\% 20$ Fundamental $\% 20$ ex periencia $\%$ 20de $\% 20$ licenciandos $\% 20 \mathrm{em} \% 20$ Computacao $\% 20 \mathrm{da} \% 20$ Universidade $\% 20$ Federal\%20da\%20Paraiba.pdf>. Acesso em: 26 set. 2019.

DANTAS, Ricardo Fidelis; COSTA, Francisco Eudes Almeida da. CODE: O ensino de linguagens de programação educativas como ferramentas de ensino/aprendizagem. 2013. Disponível em: <http://nehte.com.br/simposio/anais/simposio2013.html>. Acesso em: 22 out. 2019.

LEITE, Maria Ruth Siffert Diniz Teixeira; BRAGA, Rita de Cássia. A Introdução da Informática na Escola Pública de Ensino Básico em Minas Gerais: o Caso da Oferta do Programa 'Formação Inicial para o Trabalho' - FIT na Escola Estadual "Y". 2009. Disponível em: <http://www.anpad.org.br/admin/pdf/APS861.pdf>. Acesso em: 08 out. 2019.

PAES, Caio et al. Estratégias de Tutoria em um Curso à Distância de Programação para Alunos do Ensino Médio. 2010. Disponível em: <https://www.brie.org/pub/index.php/wie/article/view/2078>. Acesso em: 26 set. 2019. 
SOUSA, Raniere Viana de et al. Ensinando e aprendendo conceitos sobre ciência da computação sem o uso do computador: Computação Unplugged. 2010. Disponível em: <https:/ / www.br-ie.org/pub/index.php/pie/article/view/1305/1136>. Acesso em: 19 out. 2019.

SOUZA, Jéssica. Professor usa lixo eletrônico para ensinar alunos conceitos de robótica e reciclagem. 2019. Disponível em: <https:/ / razoesparaacreditar.com/ educacao/ professor-lixo-eletronico-ensinaralunos-conceitos-robotica-reciclagem/>. Acesso em: 22 out. 2019.

STINGHEN, Regiane Santos. Tecnologias na educação: dificuldades encontradas para utilizá-la no ambiente escolar. 2016. Disponível em: <https://repositorio.ufsc.br/bitstream/handle/123456789/169794/TCC_Stinghen.p df? sequence=1\&isAllowed =y >. Acesso em: 22 out. 2019.

VIEIRA, Anacilia et al. Um Relato de Experiência do Uso da Técnica Computação Desplugada. 2013. em: $<$ http://www.lbd.dcc.ufmg.br/colecoes/wei/2013/0031.pdf>. Acesso em: 17 out. 2019. 